\title{
MNAT1 is overexpressed in colorectal cancer and mediates p53 ubiquitin- degradation to promote colorectal cancer malignance
}

Shan Zhou ${ }^{1,2+}$, Jinping $\mathrm{Lu}^{2+}$, Yuejin $\mathrm{Li}^{1 \dagger}$, Chan Chen², Yongqiang Cai², Gongjun Tan², Zhengk Deng ${ }^{2}$ Zhenlin Zhang ${ }^{2}$, Zigang Dong ${ }^{3}$, Tiebang Kang $^{4}$ and Faqing Tang ${ }^{1 *}$ (D)

\section{Abstract}

Background: MNAT1 (menage a trois 1, MAT1), a cyclin-dependent kinase- inase (CAK) complex, high expresses in various cancers and is involved in cancer pathogenesis. However, echanisms underlying its regulation in carcinogenesis are unclear.

Methods: The tissue microarray of colorectal cancer (CRC) was used tolcvaluate MNAT1 expressions in CRC tissues using immunohistochemistry, CRC cell lines were also detectad MNAT1 xpression using Western-blotting. MNAT1 and shMNAT1 vectors were constructed, and transfected to cells. Cell growths of the transfected cells were observed using MTT and colony formation. The affects Of IAT1 in p53 expression were analyzed using Westernblotting and Real-time PCR. Immunoprecipitation assay was $4 /$ to analyze the interaction p53 and MNAT1, and

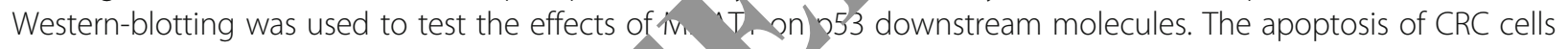
with MNAT1 or shMNAT1 were analyzed usin flow $\Delta$, metry. BABL/c athymic nude mice were used to observe the effect of MNAT1 on CRC cell growth in $v_{\text {. }}$

Results: MNAT1 was found to be overenpressed RRC tissues and cells, and MNAT1 expressions in CRC tissue samples were associated with CRC C rcinogenesis and poor patient outcomes. MNAT1-knockin increased CRC cell growth and colony formation, and AT1-knockdown dramatically decreased cell motility and invasion. MNAT1 physically interacted with p53 MNAT Increased the interaction of MDM2 with p53. Strikingly, MNAT1 mediated p53 ubiquitin-degrac a MNAT1 shortened p53 half-life, and ectopic MNAT1 expression decreased p53 protein stability. Moreovar. MNAT1 induced RAD51 and reduced p21, cleaved-caspase3, cleaved-PARP and BAX expression. MNAT1 ju hib d CRC cell apoptosis. shMANT1 decreased tumor growths in nude mice following p53 increase.

Conclusion: AT1 bir to p53, mediates p53 ubiquitin-degradation through MDM2, increases cell growth and decreases apoptosis, and finally promotes CRC malignance. MNAT1 binding to p53 and mediating p53 ubj qurin-degry ation axis represents a novel molecular joint in the p53 pathway.

Keywo '.MN $\backslash 11$, Colorectal cancer, p53, Ubiquitin, Tumorigenesis

\footnotetext{
* Correspondence: tangfaging33@hotmail.com

†Shan Zhou, Jinping Lu and Yuejin Li contributed equally to this work.

${ }^{1}$ Department of Clinical Laboratory, Hunan Cancer Hospital \&The affiliated Cancer Hospital of Xiangya School of Medicine, Central South University, Changsha 410013, China

Full list of author information is available at the end of the article
}

(c) The Author(s). 2018 Open Access This article is distributed under the terms of the Creative Commons Attribution 4.0 International License (http://creativecommons.org/licenses/by/4.0/), which permits unrestricted use, distribution, and reproduction in any medium, provided you give appropriate credit to the original author(s) and the source, provide a link to the Creative Commons license, and indicate if changes were made. The Creative Commons Public Domain Dedication waiver (http://creativecommons.org/publicdomain/zero/1.0/) applies to the data made available in this article, unless otherwise stated. 


\section{Background}

Colorectal cancer (CRC) is one of the most common malignancies worldwide, with approximately 1.2 million new cases and 608,700 deaths every year [1]. Various factors are involved in CRC incidence. CRC development is characterized by an 'adenoma- carcinoma sequence'. Overexpression of specific oncogenes or low expression of tumor suppressor genes in the epithelium results in the formation of a hyperproliferative mucosa, produces a benign adenoma, and eventually forms a carcinoma [2-4]. This process is orchestrated by different proteins, such as, Wnt, bone morphogenetic protein (BMP) and transforming growth factor (TGF)- $\beta$, along with p53 [5]. Alterations molecule pathways, such as cell cycle, cell proliferation, and apoptosis are involved in CRC onset. These alterations are responsible for colorectal epithelium carcinogenesis, which evenly confer individual susceptibility to cancers when they are germlines [6-8].

MNAT1 (menage a trois 1, MAT1) was initially identified as the third subunit besides CDK7 and Cyclin $\mathrm{H}$ in cyclin-dependent kinase-activating kinase (CAK) complex [9-12]. MNAT1 functions as an assembly factor and a substrate specificity-determining factor of CAK to promote the stability and activation of CAK [13-15]. Moreover, CAK, as the kinase subunit of general transcription factor IIH (TFIIH), is involved in transcripaon [10]. Activated CAK implicates in phosphorylati ar $d$ activating CDKs to ensure cell cycle progresoron phosphorylating retinoblastoma tumor sur sor pro tein $(\mathrm{pRb})$ to mediate cell cycle G1 exit [1 $\lambda-19]$. nportantly, CAK can phosphorylates a ser es of transc, ption factors, including p53, Oct-1, Oct-2, Oct-3, retinoic acid receptor alpha (RAR $\alpha)$, and peroxison vroliferator-activated receptor gamma (PPAR $\gamma$ thereby regulating gene transcription $[14,15]$. MNAT1 ey the above functions through its dis.n dor rains interacting with downstream molecy $\mathrm{C}$-arminal domain of MNAT1 interacts with the SDK Syclin $\mathrm{H}$ complex to stimulate CDK7 kinase 20 ity, the siled-coil domain of MNAT1 interacts with $\mathrm{XP}_{\mathrm{L}}$ nd XPB to anchor CAK to TFIIH core, whie $\mathrm{N}$-termin, domain RING finger of MAT1 is involvec S-te minal domain (CTD) phosphorylation of DAA Po nease II (PollI), which is required for gene rom ter rel-ase and transcription initiation [20]. Intact N. 41 -xpression is associated with cell cycle G1 exit, whe intrinsically programmed or RA-induced MNAT1 degradation leads to cell cycle arrest, transcription inhibition and cell differentiation [18, 21-23]. In the inhibition of RA-induced granulocytic differentiation, an inhibition of MNAT1 degradation mediates p21 expression suppression [23]. Suppressed MNAT1 triggers apoptosis [17]. In contrast, MNAT1 overexpression is associated with low p21 expression [24]. Recent reports show that MNAT1 is overexpressed in breast cancer, its expression level is associated with ER expression and patient outcome [25]. In the present study, we found that MNAT1 is highly expressed in CRC tissues, its expression was associated with CRC carcinogenesis and poor patient outcomes. Further experiments showed that MNAT1 increases CRC cell growth in vitro and in vivo, its mechanism is that MVAT1 induces p53 ubiquitin-degradation.

\section{Methods}

\section{Reagents and antibodies}

Chemical reagents for molecular biciosy w prechased from Sigma-Aldrich (St. Louis, M( ). Dulbeccys modified Eagle medium (DMEM) and ot $r$ supplements were obtained from Life Technoio. bodies against p53, p21, PARI, 'eaved-PARP, RAD51, caspase3, cleaved-ca $\mathrm{Pa}$ 3, BAX, MDM2, and BCL-2 were purchased from A oya Company (Shanghai, China). Antiboales gainst MNAT1, HSP70, GAPDH, $\mathrm{HA}$ and Flag $\mathrm{s}$ ised from Santa Cruz Biotechnology, Inc. (San Cruz, CA) and Cell Signal Technology, Inc. arly, MA).

\section{Tissue micrcarray and immunohistochemical staining}

Hu n tissue microarrays containing 80 pairs of CRC tissut and corresponding adjacent non-tumor tissues, 120 cases of CRC cancers at various stages were purchased from Outdo Biotech Company (Shanghai, China). One hundred patients enrolled into this study contained 57 males and 43 females. The median age of the patients was 46.5 age years (range $35-76$ ), < 50 age year patients were 34 cases, $>50$ age years patients were 66 cases. The tumor histology and stages were classified according to the WHO classification and the TNM staging system of the UICC, respectively. Patients in T1-T2 stages were 37 cases, and T3-T4 patients were 63 cases. Patients in N0 stage were 39 cases, and N1-N3 patients were 61 cases. Patients in M0 stage were 34 cases, and M1 patients were 66 cases. These tissue microarrays (HcolA180su10) were stained with MNAT1 antibody (dilution 1:5000) as described previously [26]. The stained tissue microarrays were evaluated independently by two pathologists who were blinded to the clinical features and clinical outcome. Each case was scored based on the intensity and percentage of cells. At least 10 high-power fields were chosen randomly, and $>1000$ cells were counted for each section. The intensity of MNAT1 staining was scored as 0 (no signal), 1+ (weak), 2 (moderate), and 3 (marked). Percentage scores were assigned as 0 , negative; $1,1-25 \%$; $2,26-50 \% ; 3,51-75 \%$; and 4, 76-100\%. The summed (extension + intensity) was used as the total score. We grouped all samples into the high expression group (total score $\geq 2$ ) and the low one (total score $<2$ ) according to the protein expression [27]. Immunohistochemical staining for MNAT1 was quantified using German semiquantitative 
scoring system as described previously [28]. Immunoreactive score (IRS) was determined using the product of the extent score and the staining intensity score.

\section{Cell lines and cell culture}

CRC cell lines, SW480, HT-29, SW620, DLD1, HCT116, loVo, RK0, HCT116 p53 ${ }^{+/+}$, HCT116 p53 ${ }^{-/-}$, and HEK293T (an embryonic kidney cell line $293 \mathrm{~T}$ ) were obtained from American Type Culture Collection (Maryland). All the cell lines were grown in DMEM supplemented with $10 \%$ fetal bovine serum (FBS) at $37^{\circ} \mathrm{C}$ and in $5 \%$ $\mathrm{CO}_{2}$.

\section{Plasmids and vectors constructing}

MNAT1 DNA fragment was generated by polymerase chain reaction (PCR) and cloned into pSIN-vector containing a FLAG, HA or V5 tag sequence. PT53 was generated using PCR and cloned into vector containing HA or FLAG. Short hairpin RNAs (sh) target MNAT1, and shMDM2 targets $M D M 2$. shMNAT1 $1^{\#} 1$ and shMNAT1 $1^{\#} 2$ were designed, and shMNAT1 and shMNAT1\#2 sequences are shown in Additional file 1: Table S1. shMDM2 was designed as described previously [29]. They were synthetized by GenePharma (Shanghai, China) and cloned into pLVX, and then PLVX-shMNAT1\#1 and PLVX-shMNAT1\#1 were obtained. HA-tagged ubiquitin was gifted by Dr. Helen Piwnica-Worms (Washington University, St. Lom As described previously $[14,30]$, the vectors ontan of various PT53 and MNAT1 domains we renerate, using Quick-Change Site-Directed Mutagen is Kit (Stratagene, California). PCR primer used are lis,ed in Additional file 2: Table S2. All the $r$ itations were verified by performing sequencing.

\section{Gene transfection and stable traiste., /cells}

Gene transfection and cell line establishment were performed as descri d p wiousiy [31]. Briefly, $1 \times 10^{4}$ of HCT116 and PNDI Mls were transfected with $2 \mu \mathrm{g}$ DNA of pSIN N-MN 1 , pLVX-shMNAT\#1, pLVXshMNAT1\#2 or pL -shscramble following the manufacture's sur.gested proto,ol. HEK293T cells were transfected with pD. pS N-MNAT1. The stably transfected cell lin pSı HCI116, MNAT1-HCT116, pSIN-DLD1, TNA 1-DL 01 , shscramble-HCT116, shMNAT1 1 1f. 110, shMNAT1 ${ }^{\#} 2$-HCT116, shscramble-DLD1, shM $: T 1^{\#} 1$-DLD1, shMNAT1 ${ }^{\#}$ 2-DLD1, pSIN-HEK293T, and PSIN-MNAT1-HEK293T were obtained by selection and further confirmed by assessing MNAT1 expression.

\section{Western-blotting and immunoprecipitation}

Western-blotting and immunoprecipitation were performed as described previously [31]. Briefly, $1 \times 10^{6}$ cells were lysed with lysis buffer [ $1 \times$ PBS, $1 \%$ Nonidet P-40, $0.5 \%$ sodium deoxycholate, $0.1 \%$ SDS, and freshly added
$100 \mu \mathrm{g} / \mathrm{ml}$ phenylmethanesulfonyl fluoride (PMSF), $10 \mu$ $\mathrm{g} / \mathrm{ml}$ aprotinin, and $1 \mathrm{mM}$ sodium orthovanadate]. Cell lysates obtained were centrifuged, and protein concentration of the clarified lysates was measured using Easy II Protein Quantitative Kit (BCA). $40 \mu \mathrm{g}$ of the supernatant protein was separated by $10 \%$ SDS-PAG 5 and transferred onto a nitrocellulose membrane. he blot was blocked with $5 \%$ non fat milk, incubated the indicated antibody, and then incubated with an $a_{1}$ " priate peroxidase conjugated secondan ntibody. The signal was developed using 4-chlore-n nap l/3,3-o-diaminobenzidine, and relative ph tographic c.ensity was quantified by a gel documentatic and aralysis system. GAPDH or HSP70 was use s a. arnal control to verify basal expression leveis an equal protein loading. The ratio of the spe $1 \mathrm{t}$ roteins to GAPDH orHSP70 was calculated. $100 \mu \mathrm{g}$ of $\mathrm{t}$. clarified supernatants were immunoprecipitate using anti-FLAG-agarose or antiHA-agarose an ma Chemical Co.). MNAT1 or p53 in the immu recipitated complexes was respectively dete by Western-blotting with anti-MNAT1 or anti-p5: zitin, dy.

\section{Apo, sis analysis}

nop osis analysis was performed as described previo. $y$ [32]. Briefly, $1 \times 10^{4}$ cells of shscramble-HCT116, hMNAT1 ${ }^{\#} 1$-HCT116, shMNAT1 ${ }^{\#} 2$-HCT116, pSINHEK293T, and pSIN-MNAT1-HEK293T were seeded on six-well plates and cultured to reach $70 \%$ confluence, and were treated with 10 or $80 \mu \mathrm{g} / \mathrm{ml} 5$-fluorouracil (5-FU). After $24 \mathrm{~h}$ treatment, the cells were collected by $0.02 \%$ trypsin without eathylene diamine tetra acetic acid (EDTA), and stained with annexin V-EGFP (Enhanced Green Fluorescent Protein) and propidium iodide (KeyGen Biotec) according to the manufacturer's recommendations, and analyzed by flow cytometry.

\section{MTT and colony formation assays}

Cell growth was determined by performing MTT [3-(4,5-dimethyl-2-thiazolyl)-2,5-diphenyl-2 - $\mathrm{H}$-tetrazolium bromide] assays as described previously [33]. Briefly, pSIN-HCT116, pSIN-MNAT1-HCT116, pSIN-DLD1, pSIN-MNAT1-DLD1, shscramble-HCT116, shMNAT1 ${ }^{\# 1-}$ HCT116, shMNAT1 ${ }^{\#} 2$-HCT116, shscramble-DLD1, shMNAT1 ${ }^{\#} 1$-DLD1, and shMNAT1 ${ }^{\#} 2$-DLD1 cells $(1 \times$ $10^{3}$ ) were seeded in 96-well microplates. The cells were cultured for the indicated time, followed by incubation with MTT for $4 \mathrm{~h}$. Optical density (OD) was determined at $450 \mathrm{~nm}$ using a microplate reader. Measurements were acquired once per day for $5 \mathrm{~d}$. For the colony-formation assay, the cells were plated at a density of 500 cells/well in six-well plates and were cultured for $12 \mathrm{~d}$. Colonies were fixed in methanol, stained with $0.5 \%$ gentian violet, and 
counted [34]. Results are presented as mean \pm SD of three independent experiments.

\section{Real-time PCR}

Real-time PCR was performed as described previously [30]. Briefly, $1 \mu \mathrm{g}$ DNase-treated RNA was reverse transcribed using Revert AidTM First-Strand cDNA Synthesis Kit (MBI Fermentas, USA) according to the manufacturer's instructions. Threshold cycle $(\mathrm{Ct})$ value of each sample was determined using Platinum SYBR Green qPCR SuperMix-UDG with ROX (Invitrogen) in ABI 7900HT Real-Time PCR System (Applied Biosystems, Foster City, CA). Sequences of primers used are shown in Additional file 3: Table S3. Relative mRNA expression of each target gene was normalized to the expression of the housekeeping gene GAPDH. Relative mRNA level was calculated as two power values of $\Delta \mathrm{Ct}$ ( $\mathrm{Ct}$ value of GAPDH Ct of target gene).

\section{Tumor growth assays in vivo}

In vivo tumor growth assays were performed as described previously [35]. Briefly, female BABL/c athymic nude mice (age $4 \mathrm{w}$ ) were obtained from an animal center of Guangdong Province (Guangzhou, China). All ani mal experiments were performed according to he National Institutes of Health Animal Use Guidelir is en the Use of Experimental Animals. The nude mice re subcutaneously injected $2 \times 10^{6}$ cells scrambr

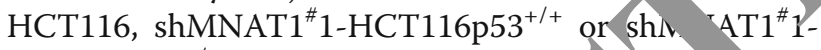
HCT116p $53^{-/-}$, 6 mice per group. Ty n10r sizes o Mude mice were measured every 2 or $3 \mathrm{~d}$ and tumor volume was estimated. After 17 days, the mi were uthanized, and the tumors were removed $n$ nd welg.....

\section{Cell invasion and motilit, say}

Cell invasion and $r$ tilit were assayed according to the methods descrbed eviously with minor modifications [36]. CF nvasion and motility of shscrambleHCT116, shMINA \#1-HCT116, shscramble-DLD1, and shMNAT ${ }^{+} 1$ - DLD1) cells were detected using Boyden chambe vion assay in vitro. Briefly, for invasion assay, ma+ $r e l(2.9 / 50 \mathrm{ml}$, Collaborattiv Biomedical Products, edfo d, MA, was added into the chamber to be $8 \mathrm{~mm}$ p siza polycarbonate membrane filters. The cells were tryps $\angle$ ed to be suspension cells, and were seeded into the Boyden chamber (Neuro Probe, cabin John, MD) at the upper part at a density of $1.5 \times 10^{4}$ cells/well in $50 \mu \mathrm{l}$ of serum-free medium, and then incubated for $12 \mathrm{~h}$ at $37^{\circ}$ C. The bottom chamber also contained standard medium with $20 \%$ FBS. The cells invaded to the lower surface of membrane were fixed with methanol and stained with hematoxylin and eosin. Invaded cell numbers were counted under a light microscope. The motility assay was carried out as described in the invasion assay with no coating of matrigel.

\section{Protein half-life detection}

Protein half-life was determined as described previously [37]. Briefly, pSIN- and pSIN- MNAT1-HEK293, sh cramble- and shMNAT1 $1^{\#} 1$ - LoVo cells were treated with 10 $\mathrm{mg} / \mathrm{mL}$ cycloheximide $(\mathrm{CHX})$, and the treated were collected at indicated time points after $\mathrm{CHX}$ treatmo for 0, 20, 40, 60, 90 and $120 \mathrm{~min}$. Protein of collect d cells was extracted for performing W/cotern-ttirg with anti-p53 or anti-MNAT1 antibod GAPDH y as used as an internal control to verify bas level expression and equal protein loading. The at tan to HSP70 was counted, and half-life time of the teins was calculated.

\section{Ubiquitination assav}

In vivo ubiquitiat assay was performed as described previously [3\%, Q] 4 , HEK293T cells were stable transfected with $\mathrm{N}$-MNAT1, LoVo cells were stable transfecte th shscramble, shMNAT1 $1^{\#} 1$ or $\operatorname{shMNAT}^{\#} 2$. The stable ceil m, es were cotransfected with plasmids expressing 3Fl o-p53 and HA-ubiquitin. The cells were lysed In 1 buffer. The cell lysates were centrifuged. The supernatan were immunoprecipitated with anti-Flag agarose, Whe immunocomplexes were immunoblotted using and-HA antibody.

\section{Results}

\section{MNAT1 is highly expressed in CRC cells and tissues}

To clarify MNAT1 expression in CRC cells, CRC cell lines, SW480, HT-29, SW620, DLD1, RK0, LoVo, and HCT116 cells were detected MNAT1 expression using Western-blotting. Compared with HEK293T, MNAT1 protein levels were mostly elevated in SW480, HT-29, SW620, DLD1, RK0, LoVo, and HCT116 (Fig. 1a). HCT116 and DLD1 had a relatively low MNAT1 expression, and LoVo had a high expression (Fig. 1a), they were used to perform the next experiments. To clarify whether MNAT1 overexpresses in CRC tissues, a tissue microarray containing 80 pairs of CRC, adjacent non-tumor tissues, and other 20 CRC tissue samples was used to detect MNAT1 expression. The immunohistochemical results showed that MNAT1 was significantly high in CRC tissues when compared with the matched adjacent normal tissues (Fig. 1b, c. $p=0.042$ ). The positive rates of MNAT1 expression were compared in normal colorectal, primary CRC, and metastatic CRC tissues. The positive rates of MNAT 1 were $11.3 \%$ in normal tissues, $55.9 \%$ in primary CRC and $56.1 \%$ in metastatic CRC tissues, respectively (Table 1). MNAT1 was significantly upregulated in primary CRC (Table 1. $p=$ 0.031) and metastatic CRC tissues (Table 1. $p=0.033$ ), whereas no difference of MICAL2 between primary CRC 
A

B

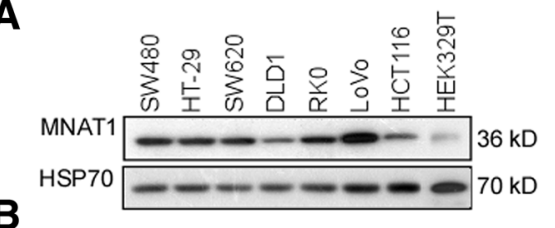

0
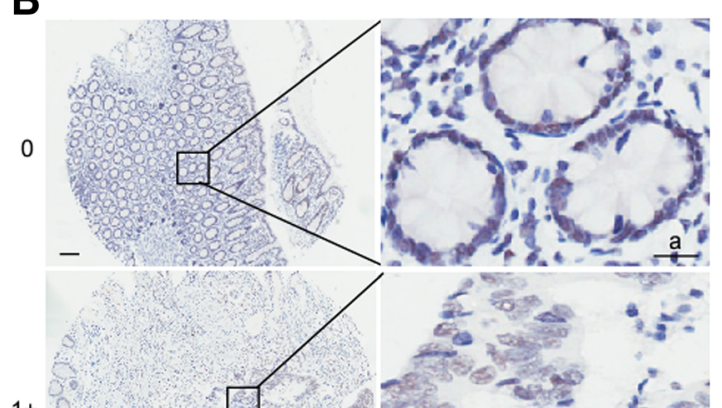

$1+$
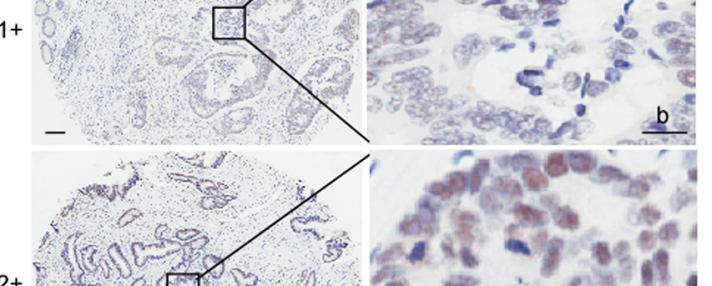

$2+$

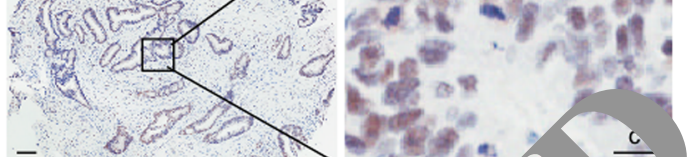

$-$
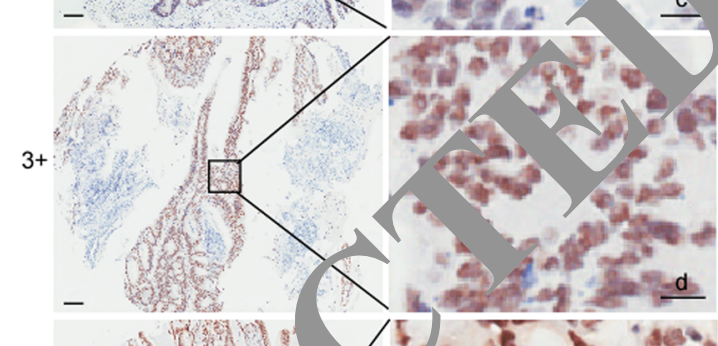

in

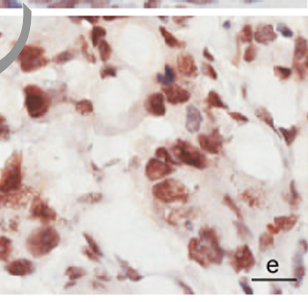

Fig. 1 MNAT1 xpre ns in CRC and its association with CRC patient outcomes. A, MNAT1 expressions were detected in SW480, HT-29, SW620, DLD1, RKO No, HCT1, ad HEK329T using Western-blotting. B, MNAT1 expressions in CRC and non-tumor tissues microarray were detected using in nunphistochemstry (IHC). a, negative, scored as 0 ; b, weakly positive, scored as 1 ; c, moderately positive, scored as 2; d, positive, scored as 3; e, $\beta \quad v_{-}$, scor $d$ as 4; Scale Bar, $100 \mu \mathrm{m}$. C, MNAT1 expression levels in CRC tissue samples were quantified using a German semiquantitative scoing syst Rel-tive expressions in CRC tissues and non-tumor tissues were statistically analyzed using Mann-Whitney $U$ test. The dots represent scort D, The croff value of MNAT1 immunoreactive score is 4.6 according to the ROC curve, and the AUC is 0.933 . ROC, receiver operating AUC, area under the curve. E, The overall survival of CRC patients with high (49) or low (51) MNAT1 expression. ${ }^{*}, p<0.05$

and metastatic CRC tissues. In addition, MNAT1 level may be used for the CRC diagnosis, and the area under the curve (AUC) was calculated. Cut off of MNAT1 was 4.6 (Fig. 1d. AUC $=0.933, p=0.013$ ). Sensitivity was $87.6 \%$, and specificity was $67.7 \%$. The association of MNAT1 expression with CRC stages was analyzed. MNAT1 expression was not correlated with $\mathrm{T}$ stage (original tumor size and nearby tissue invasion) (Table 2. $p=0.882$ ), $\mathrm{N}$ stage (lymph node metastasis) (Table 2. $p=0.891$ ), nor $\mathrm{M}$ stage (distant metastasis) (Table 2. $p=0.897$ ). The patients with high MNAT1 displayed shorter overall survival than low MNAT1 expression (Fig. 1E, $p=0.011$ ). These data strongly suggest that high MNAT1 has oncogenic potency and is associated with CRC poor outcomes. 
Table 1 MNAT1 expressions in normal colorectal, primary CRC, and metastatic CRC tissues

\begin{tabular}{llllll}
\hline & & \multicolumn{4}{l}{ MNAT1 } \\
\cline { 3 - 6 } & $n$ & - & + & $\%$ & $P$ \\
\hline NC & 80 & 71 & 9 & 11.3 & \\
CRC & 59 & 22 & 33 & 55.9 & $0.031^{\text {a }}$ \\
MCRC & 41 & 17 & 23 & 56.1 & $0.033^{b}$
\end{tabular}

NC normal colorectal tissue, CRC primary CRC, MCRC metastatic CRC tissues ${ }^{\mathrm{a}} \mathrm{CRC}$ versus $\mathrm{NC} ;{ }^{\mathrm{b}} \mathrm{MCRC}$ versus NC

\section{Oncogenic properties of MNAT1 in CRC cells}

HCT116 and DLD1 cells with low MNAT1 expressions were used to investigate MNAT1 function in CRC cell growth. We constructed MNAT1 expression vector, pSIN-MNAT1. HCT116 and DLD1 cells were transfected with pSIN-MNAT1. MNAT1 was detected in the transfected cells using Western-blotting, and the results displayed that MNAT1 was overexpressed in the transfected cells (Fig. 2A). Viability of the transfected cells was determined by performing MTT assay. MTT data showed that the growth kinetics of HCT116 (Fig. 2B-a. $p<0.05)$ and DLD1 cells (Fig. 2B-b. $p<0.05$ ) increased when being transfected with MNAT1. Further, cell colony formation of the transfected cells was detected. MNAT1 dramatically increased colony formation of HCT116 (Fig. 2C-a, b, c. $p<0.05$ ) and DLD1 ce $\left(\mathrm{F}_{1}\right.$ $2 \mathrm{C}$-d, e, f. $p<0.05)$. Next, shMNAT1 ${ }^{\#} 1$ and shiviNA. were designed to target MNAT1, and pLVX, MNAT1) and pLVX-shMNAT1 ${ }^{\#} 2$ were constructer. HC, 6 and

Table 2 MNAT1 expressions in CRC samp s at various clinical stages

\begin{tabular}{|c|c|c|c|c|}
\hline Characteristic & Cases & $M N \digamma^{-1}$ & IOTI & $p$ \\
\hline \multicolumn{5}{|l|}{ All patients } \\
\hline \multicolumn{5}{|l|}{ Gender } \\
\hline Male & & & 22(38.6) & \multirow[t]{2}{*}{0.817} \\
\hline Female & & $29(67.4)$ & 14(32.6) & \\
\hline & & $16(47.1)$ & $18(52.9)$ & \multirow[t]{2}{*}{0.770} \\
\hline & & $35(53.0)$ & $31(47.0)$ & \\
\hline & 37 & $19(51.3)$ & $18(48.7)$ & \multirow[t]{2}{*}{0.88} \\
\hline$T 3 / 4$ & 63 & $34(53.9)$ & $29(46.1)$ & \\
\hline \multicolumn{5}{|l|}{ N stage } \\
\hline NO & 39 & $17(43.6)$ & $22(56.4)$ & \multirow[t]{2}{*}{0.89} \\
\hline N1-N3 & 61 & $29(47.5)$ & $32(52.5)$ & \\
\hline \multicolumn{5}{|l|}{ M stage } \\
\hline MO & 34 & $18(52.9)$ & $16(47.1)$ & \multirow[t]{2}{*}{0.897} \\
\hline M1 & 66 & $35(53.0)$ & $31(47.0)$ & \\
\hline
\end{tabular}

DLD1 were infected with pLVX-shMNAT1 1 and pLVXshMNAT $1^{\#} 2$. Western-blotting and real-time PCR were performed to evaluate the efficiency of $\operatorname{shMNAT}^{\#} 1,2$. The results showed that the shMNAT1 ${ }^{\#} 1,2$ effectively blocked MNAT1 protein (Fig. 2D-a) and mRNA expression (Fig. 2D-b, c). After MNAT1 was knock down, HCT116 (Fig. 2E-a, $p<0.05$ ) and DLD1 (Fig. $-\mathrm{b} p<$ 0.05 ) growths were decreased when compared the scramble control. Simultaneously, motility and in in of the transfected cells were also obs red, 10 fields were randomly selected and count uthe raded cells per cell well. The results shower that the $\mathrm{m}$, stility and invasion of MNAT1-knockdown lls were dramatically decreased when compared th ocramble group (Fig. 2F-a, b, c; Fig.2G-a b, c. $p$ ר. 05).

\section{MNAT1 down-regulc sexpressions of p53}

The above res red that MNAT1 is associated with CRC cell gro h.We next investigated mechanisms underlyin "NAT1-regulated cell growth, and focused on MNAT1 ieg rating p53 and its molecular mechanism. CRC cells were transfected with MNAT1 expression ve s, p53 and PT53 mRNA expressions were detecte The results showed that p53 expressions signifit1. decreased after being transfected with MNAT1 (F) g. 3A-a, b), but p53 mRNA expression did not change (Fig. 3B). To observe the dose effect of MNAT1 on p53 expression, HEK293T cells were exogenously transfected HA-p53 and various dose Flag-MNAT1, and then p53 was detected. p53 expression decreased along with MNAT1-dose increase, displaying a dose-dependent manner (Fig.3C-a, b). To further observe the effect of MNAT1 silencing on p53 expression, LoVo cells were transfected with shMNAT1\#1 and \#2, and p53 expression was detected. The results showed that p53 expression was increased when MNAT1 was silenced (Fig. 3D). Doxorubicin (DOX), an anticancer regent, has been proved to increase p53 expression [39]. Dox was used to treat HCT116 cells at various concentrations, and p53 and MNAT1 expressions were analyzed. MNAT1 gradually decreased along with DOX concentration increase, while p53 gradually increased, displaying significantly concentration-dependent (Fig. $3 \mathrm{E})$. In the next, HCT116 cells were transfected with pSIN-MNAT1, and then the transfected cells were treated with MG132, a specific proteasome inhibitor to inhibit MNAT1 expression, and p53 expression was observed. MG132 substantially rescued the raise of p53 protein level caused by pSIN-MNAT1 (Fig. 3F), further this results were confirmed with DOX reducing MANT1 expression (Fig. 3G). These suggest that MNAT1 decreases p53 expression by the proteasome. 
A

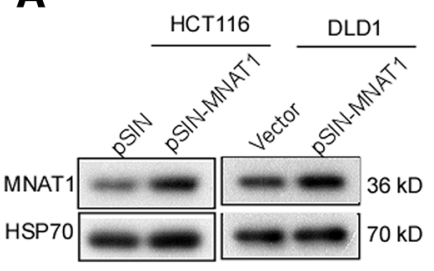

C
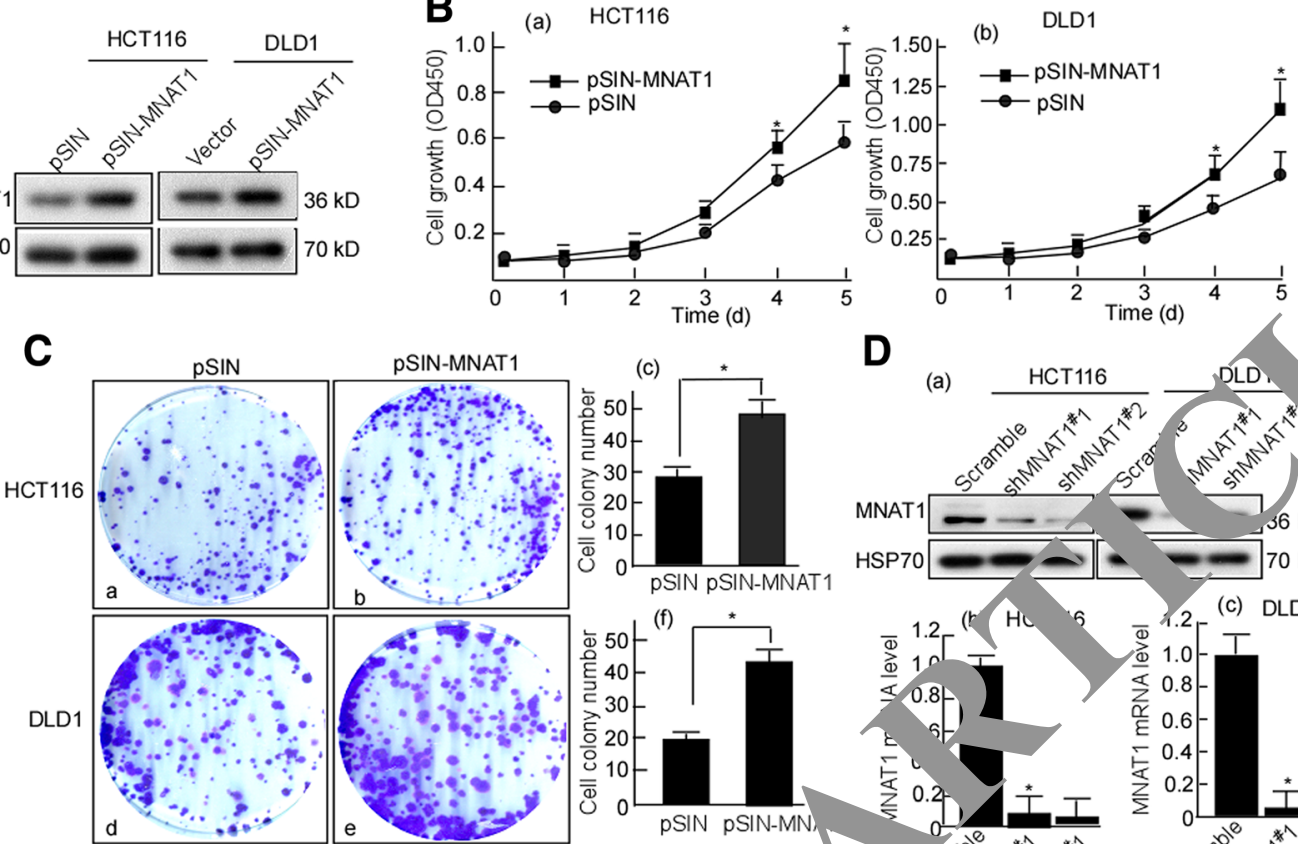

D

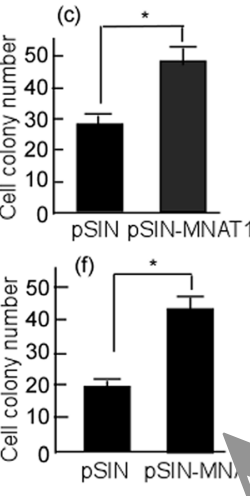

E

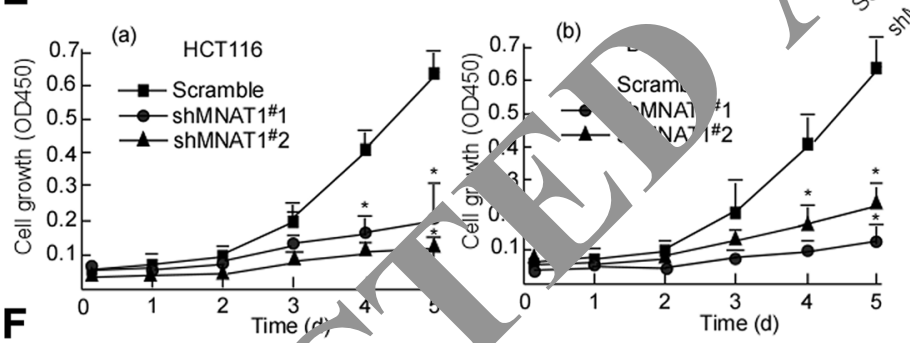

F

(a) Scramble ShMNAT1 ${ }^{\# 1}$ ShMNAT1 ${ }^{*} 2$

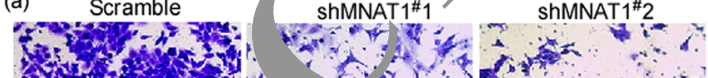

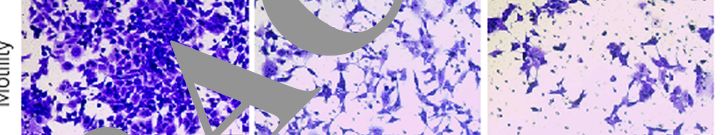

H.t.

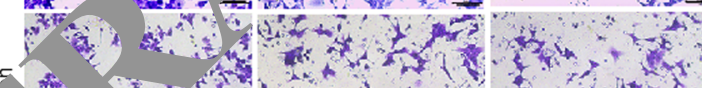

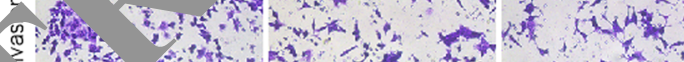

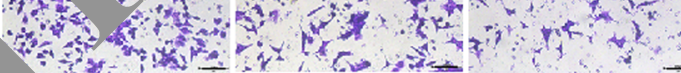

G
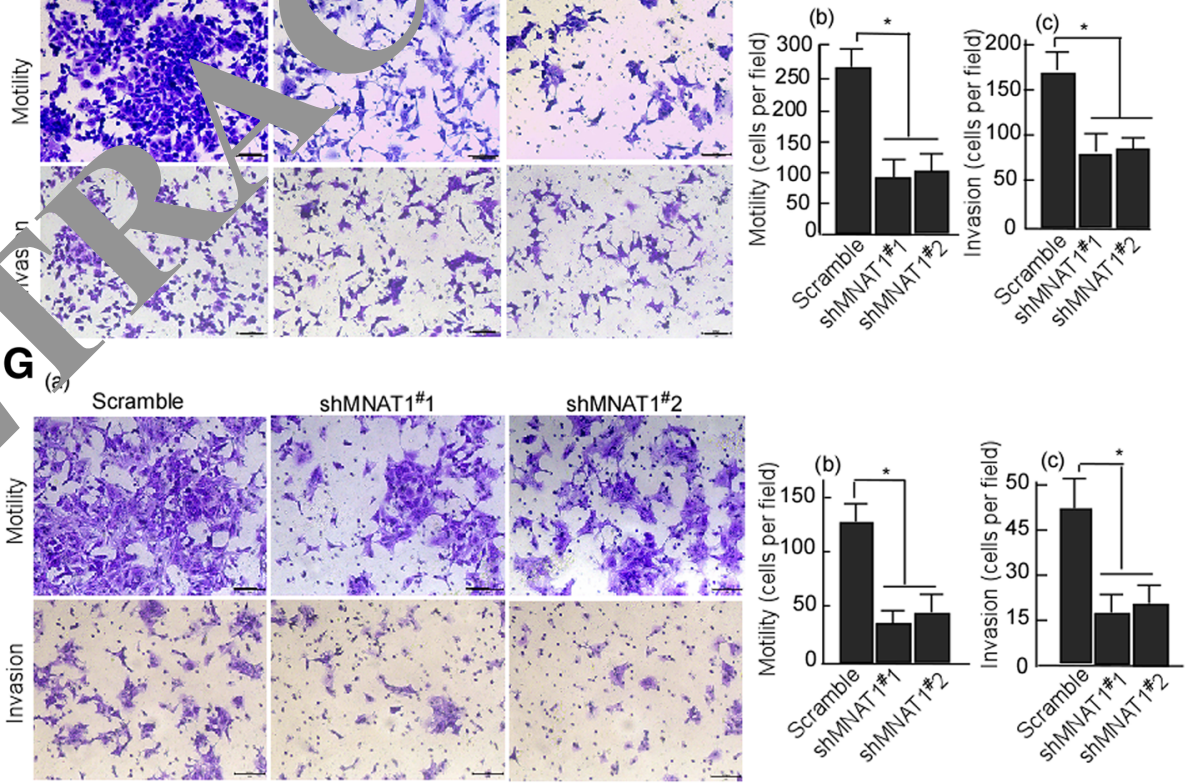

Fig. 2 (See legend on next page.) 
(See figure on previous page.)

Fig. 2 MNAT1 increases CRC cell growth and MNAT1-knockdown decreases cell growth. HCT116 and DLD1 cells were transfected with pSIN-MNAT1 respectively. A, MNAT1 expressions in the transfected cells were detected using Western-blotting. B, Viability of MNAT1 transfected-HCT1 16 (a) and DLD1 (b) cells was measured using MTT. C, Colony formation of the transfected- HCT116 and DLD1 cells was detected using colony formation assay. a, HCT116 with pSIN; b, HCT116 with pSIN-MNAT1; c, Cell colony numbers of the transfected HCT116; d, DLD1 with pSIN; e, DLD1 with pSIN-MNAT1; f, Cell colony numbers of the transfected DLD1. D, HCT116 and DLD1 cells were transfected with pLVX-shMNAT1 ${ }^{\# 10 r}$ pLVX-shMNAT1 ${ }^{\# \text {, }}$ respectively. MNAT1 protein (a) and mRNA (b, c) in the transfected cells were detected using Western-blotting or Real-time PCR, respec ively. E, Viability of shMNAT1 transfected-HCT116 (a) and DLD1 (b) cells was measured using MTT. F, Motility and invasion of HCT116 cells th ) shMNAT1s were detected with Boyden chamber invasion assay (a), the motility (b) and invasion (c) cells were counted. G, Motility ana invasion of DLD1 cells with shMNAT1s were detected (a), the motility (b) and invasion (c) cells were counted. All experiments were repec three times. Data are presented as means \pm S.D. of three independent experiments and were statistically analyzed using Sty t's test. Scone bar, $100 \mu \mathrm{m} .{ }^{*}, p<0.05$

\section{MNAT1 interacts with p53}

In this step, we first performed endogenous immunoprecipitation assay to examine whether MNAT1 directly interacted with p53. LoVo cells with high expression MNAT1 were used to immunoprecipitate p53 and MNAT1, and then p53 and MNAT1 were detected in the immunocomplexes using Western-blotting. The results showed that p53 was detectable in MNATy-im unoprecipitated complexes, and MNAT1 was also tecu in p53 immunocomplexes (Fig. 4A). To arther firm the interaction of MNAT1 with p53, HE $93 \mathrm{~T}$ cel.s were contransfected with HA-p53 and Flag-MN 1, and then their interaction was determined US. immunoprecipitation. Immunoprecipitation resul hat MNAT1 bound to p53 (Fig.

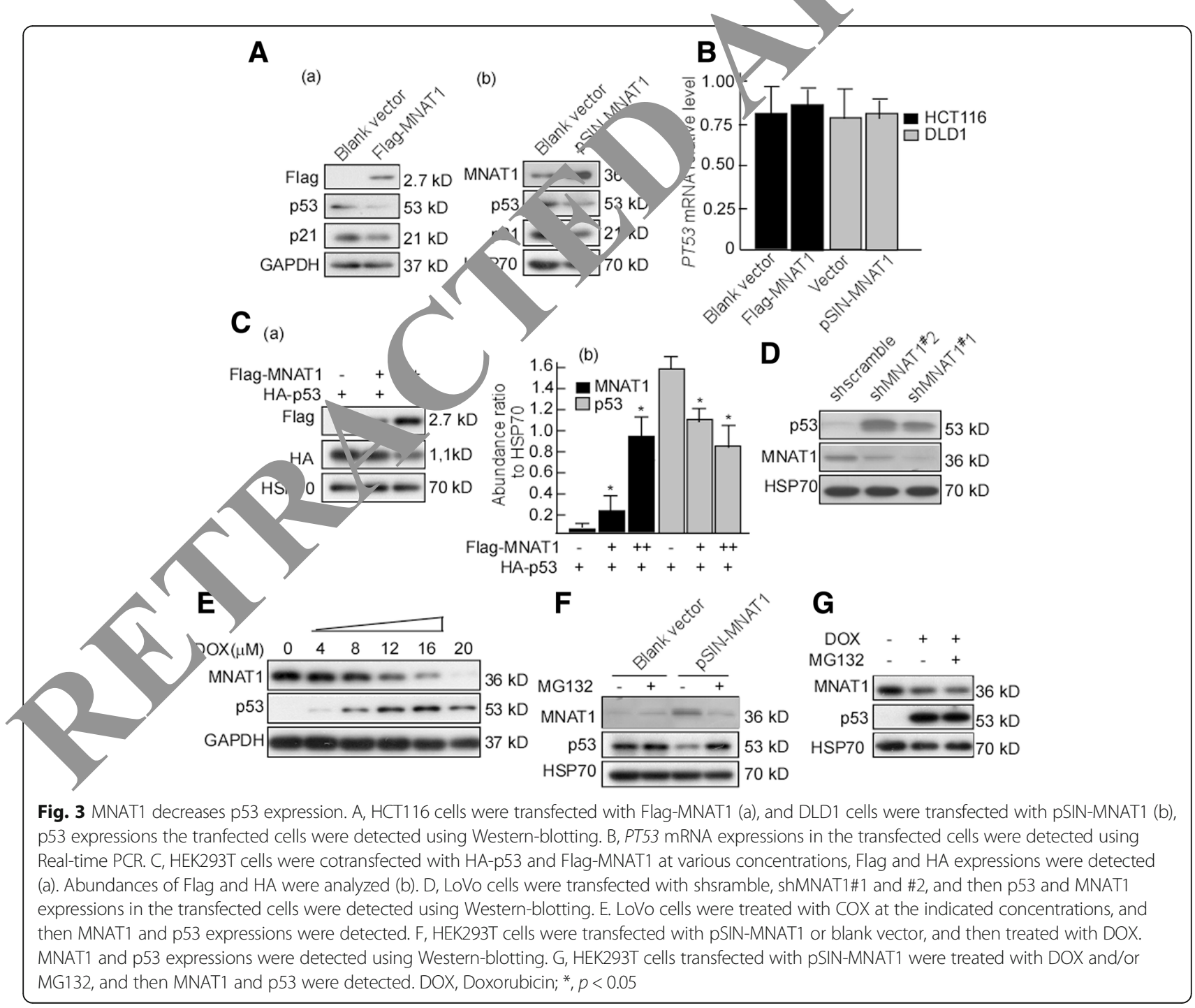




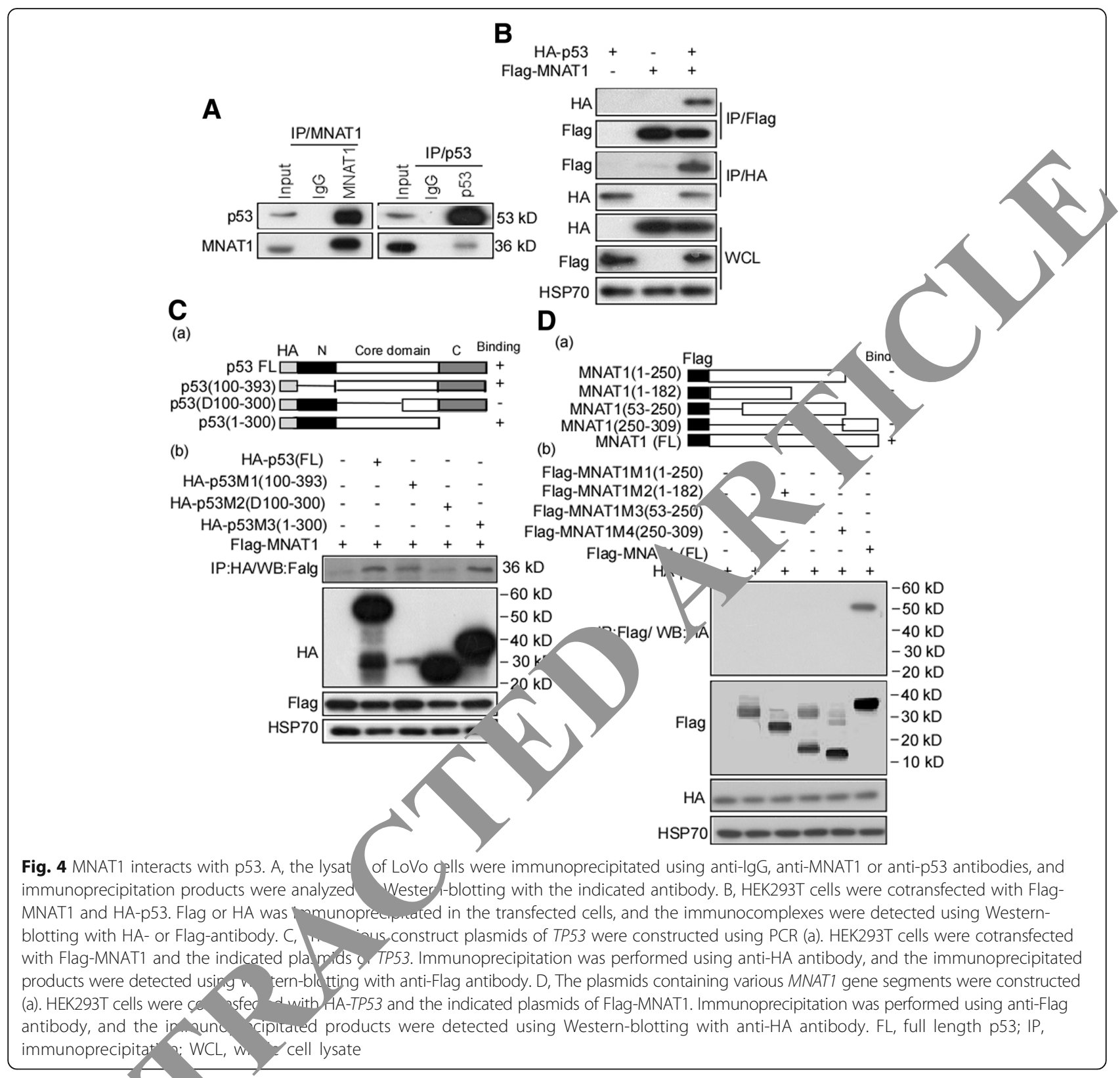

4B). There findings il dicated that MNAT1 interacts with p53. Ne w-de ermined the domains of p53 involved in thic tera $n$ asing p53- and MNAT1-expressing plasids. The plasmids expressing various p53 domains were co rucud (Fig. 4C-a). HEK293T cells were transfected with $c$ indicated plasmids, and the immunoprecipitation was performed to identify the interacting domains of p53. The results showed that the domains containing residue 1300 displayed a binding band with MNAT1, while the deletion of residues 100-300 had no binding signal (Fig. 4C-b). This indicated that the domain of p53 residues 100-300 was necessary and sufficient for interaction with MNAT1. Simultaneously, to determine the domains of MNAT1 participated in the binding of MNAT1 to p53, the plasmids containing various MNAT1 domains were constructed (Fig. 4D-a) and the plasmids were transfected into HEK293T cells, the immunoprecipitation was performed to identify the interacting domains of MNAT1. The results showed that only full-long MNAT1 interacted with p53, and MNAT1 mutants containing domain deletion could not interact with p53 (Fig. 4D-b).

\section{MNAT1 promotes ubiquitin-degradation of $\mathrm{p} 53$}

The above results suggest that MNAT1 decreases p53 protein level, while p53 mRNA level did not change, indicating that MNAT1 may regulate p53 at posttranscriptional level. We speculated that MNAT1 affects p53 proteolysis. To confirm this, HEK293T cells 
were co-transfected with v5-MNAT1 and Flag-p53, and then p53-ubiquitin was detected. The results showed that Flag-p53 poly-ubiquitin was stronger in the MNAT1 transfect than the blank control (Fig. 5a). Further, we used shMNAT1 to knockdown MNAT1 expression, and observed whether the reduced-MNAT1 decreases p53 ubiquitination. The results showed that Flag-p53 ubiquitination was dramatically decreased when being transfected shMNAT1 (Fig. 5b). Additionally, we investigated whether MNAT1 could exactly mediate endogenous p53 ubiquitination. pSIN-MNAT1 was transfected into HCT116, and p53 ubiquitination was observed. The endogenous p53 ubiquitination significantly increased when transfected with pSIN-MNAT1 (Fig. 5c). We also observed the effect of MANT1knockdown on endogenous p53 ubiquitination. p53 ubiquitin-degradation dramatically decreased (Fig. 5d), and the cotransfection with shMNAT1 $1^{\#} 1$ and $\operatorname{shMNAT1}{ }^{\#} 2$ had less p53 ubiquitin-degradation than the single one (Fig. 5e). The rescue experiments of MNAT1-mediated p53 ubiquitin-degradation were performed. MANT1HEK293 cell was treated with MG132, and then p53 ubiquitination was detected. The results showed the p53 ubiquitin-degradation significantly increased in the MNAT1- transfected cell, this p53 ubiquitin-des ation was decreased by MG132 treatment (Fig. 5e). Collec 1 , these results indicate that MNAT1 increa p53 u' iquitination, thus promoting its proteasomar degr. tion.

\section{MNAT1 shortens half-time p53}

The above findings showed + 1 promotes p53 ubiquitin-degradation. Noreov ubiquitin-proteasome is a highly effective tein-desradation pathway in eukaryotic cells [40-42]. oxt step, we detected the

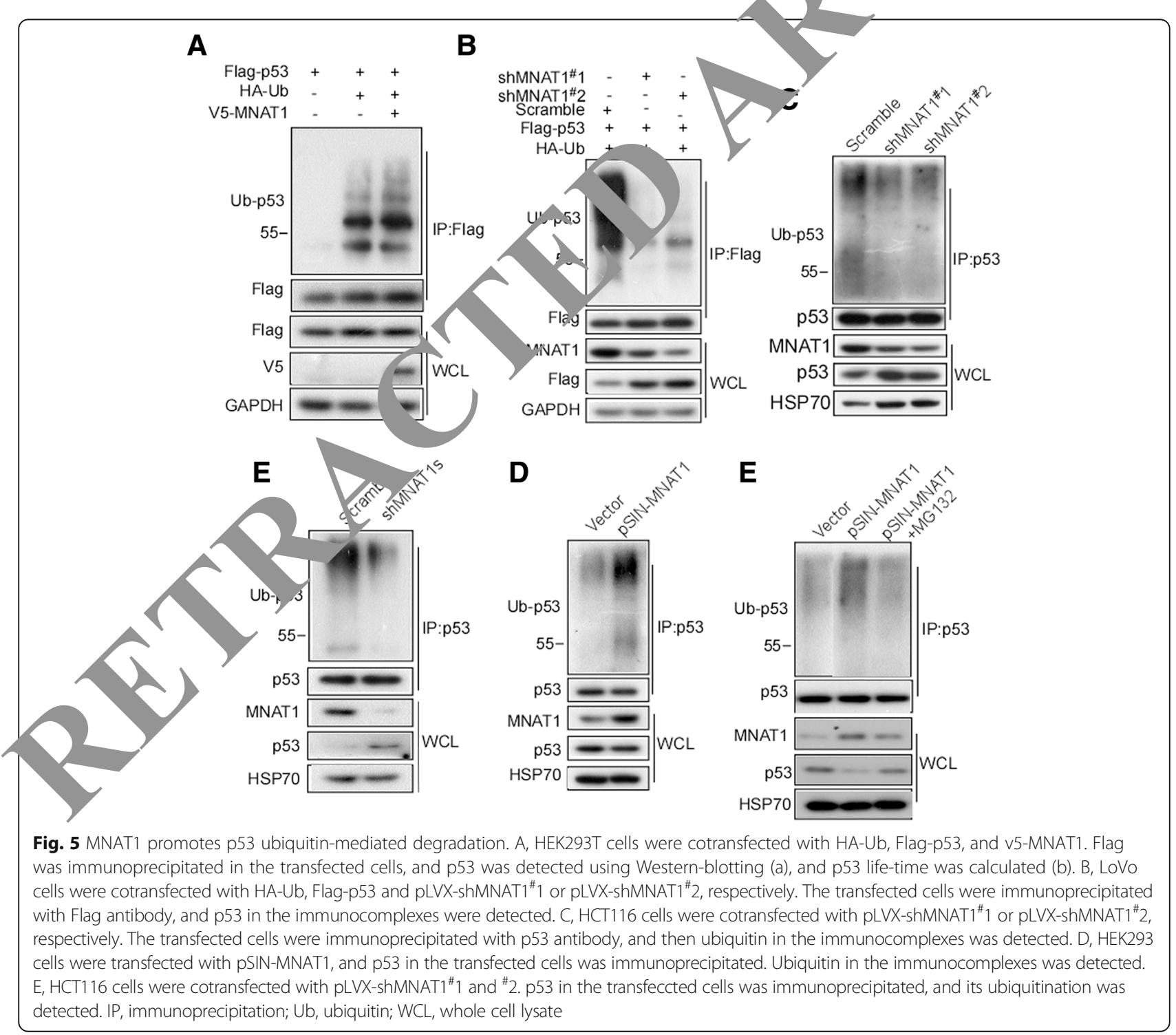


half-life time of p53 when MNAT1 knockin and MNAT1 knockout. HEK293 cells were transfected with pSIN-MNAT1, and treated with CHX. The half-life time of endogenous p53 protein was measured in the treated cells. The half-life time of endogenous p53 was shorter in the transfect with pSIN-MNAT1 than in the control cells (Fig. 6A-a, b). Simultaneously, LoVo cells were knockdown MNAT1 with shMANT1 ${ }^{\#} 1$, and p53 half-life was analyzed. The data showed that p53 half-life time was longer in the cells with shMNAT1 transfection than the control (Fig. 6B-a, b). E3 ubiquitin ligase murine double minute (MDM2) is the most critical negative regulator for p53 protein stability. MDM2 binds to p53 and ubiquitinates it for proteasomal degradation [43-45]. Therefore, we tested the effect of MNAT1 on the interaction of MDM2 with p53. MDM2 binding to p53 was dramatically increased in the cells with MNAT1 transfection, while MDM2 interacted with p53 was significantly decreased when MNAT1 knockdown (Fig. 6C-a, b. $p<0.05$ ). To further confirm whether MNAT1-mediated p53 decrease is through MDM2, stable cell line, MANT1-HEK293 cells were knockdown MDM2 with shMDM2 to observe p53 expression. The results showed that MNAT1 significantly decreased p53 expression, but p53 decrease was not significant when MDM2 knockdown (Fig. 6D). These data suggested MNAT1 mediates p53 ubiquitin t' ug increasing interaction of MDM2 with p53.

\section{MNAT1 regulates $p 53$ downstream genes}

The above findings showed that MN $\mathrm{T} 1$ decreas s $\mathrm{p} 53$ through ubiquitin-degradation. In the ext step, we investigated whether MNAT1-decreased ps ffecto p53 downstream genes. HEK293T cell were transfected with pSIN-MNAT1, and then p53, p2 , se, PARP, RAD51, $\mathrm{BAX}$, and Bcl2 were ter p53, 21, cleaved- caspase 3, cleaved-PARP and $\mathrm{B}$ - we decreased in the transfected cells, and RAD57 was creased (Fig. 7A). To further probe whether VAT1 re alating p21, PAPR, BAX, and RAD51 is thoug 53, HCT116 $\mathrm{p}^{+/+}$and HCT116 $\mathrm{p} 53^{-/-}$ceils were use, to determine whether $p 53$ gene is essentia Tr. re vults showed that MNAT1-knockdown inc sed 121 , and BAX expressions, and decreased ARK and R.D51 expression in HCT116 p53 ${ }^{+/+}$, did not in 'Cr.o p53 $3^{-1-}$ cells (Fig. 7B). DOX is an anticancer rege it has proved to inhibit synthesis of RNA and DNA [46]. The previous data showed that DOX inhibits MNAT1 expression. To further clarify whether DOX decreased-MNAT1 also regulates p53 downstream molecule, HCT116 cells were transfected with shMNAT1 or pSIN-MNAT1, and then treated with DOX. The results showed that the cleaved PARP was not increased when transfected with MNAT1, but cleaved PARP was increased when being transfected with shMANT1 (Fig. 7C).
Whether 5-FU-reduced MNAT1 regulates p53 downstream molecules was investigated. Fas, a p53 target gene, was decreased in the transfect with MANT1, but did not change in the transfect with shMNAT1 (Fig. 7D). Simultaneously, apoptosis in MNAT1-knockdown cells was also detected, there was no difference (data not shown). So, 5-FU was used to treat MNAT1-knockdown cell and cell apoptosis was detected using flow cytometry. Th. esults showed that $\operatorname{shMNAT1}^{\#} 1$ and $\operatorname{shMNAT} 2^{\#} 2$ signit enhanced 5-FU-induced apoptosis (Fig. F-b, c, f. $p<$ 0.05 ), and pSIN-MNAT1 reduced 5- 5 ind 4 apoptosis (Fig. 7E-e, f. $p<0.05$ ). Collectively, MNAT1 de, reases p53 expression, and regulates p53 dov tream/molecules, reduced cell apoptosis.

\section{MNAT1 promotes CRC 9 , th in viso}

The above-mentioned resi showed that MNAT1 increased CRC ceil g wth anc colony formation, and also found MNAT or $\quad$ 53 ubiquitin-degradation, and regulated p53 do tream molecules. In the next step, we furthe firmed whether MNAT1 exerts oncogenic effect in Vivo/Shscramble-HCT116, shMNAT1 ${ }^{\# 1-}$ HCT116 cels, were subcutaneously injected into the dorSan nks of mice. The tumors of mice were measured ver $2 \mathrm{~d}$. After 17 days, the mice were euthanized, and nc weights were measured. Data showed that the tumors of mice injected with shMNAT1 ${ }^{\#} 1$-HCT116 were smaller than that of the shscramble mice (Fig. 8A, B. $p<$ $0.05)$. MNAT1 and p53 expression was detected in these tumor tissues using immunohistochemistry, and positive cells were counted in 10 fields of the IHC stained section under microscopy. Immunohistochemical results showed that MNAT1 expression was low, and p53 was high in the tumor tissues of shMNAT1 ${ }^{\# 1-H C T 116}$ when compared with the shscramble group (Fig. 8C-a,b. $p<$ $0.05)$. These results indicated that MNAT1 promoted $\mathrm{CRC}$ growth through down-regulating p53 in vivo. Summarily, MNAT1 binds to p53, and mediates p53 ubiquitin-degradation through MDM2, decreased p53 functions, and finally promotes CRC growth (Fig. 8D).

\section{Discussion}

The adenoma-carcinoma multistage theory has been documented for CRC carcinogenesis. In this carcinogenesis process, mutation activating multiple oncogenes and inactivating tumor-suppressor genes accumulate in normal colonic epithelial cells and cause adenomas [4]. Our results suggest that MNAT1 is a novel gene in CRC pathogenesis. This is based upon the following three results. (1) MNAT1 was highly expressed in CRC cells, and its expression was associated with advanced CRC development and low 5-year survival rate. (2) MNAT1 increased CRC cell malignant activity. (3) In vivo, MNAT1-knockdown decreases tumor growth. These results suggested that 
A

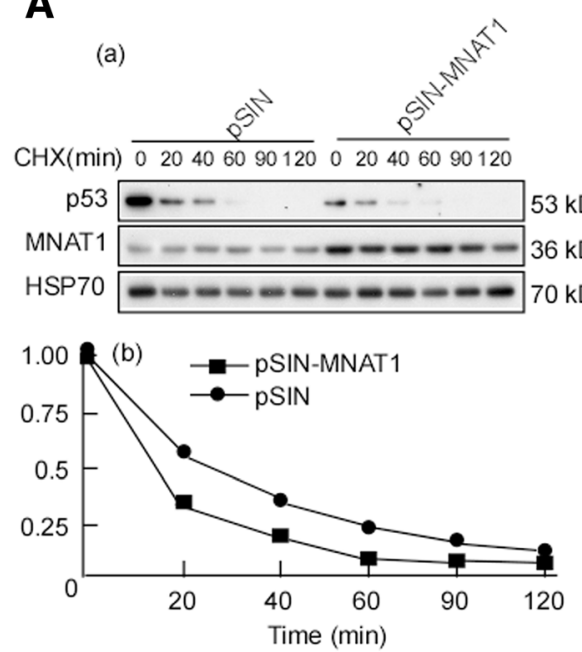

$\mathbf{C}_{(\mathrm{a})}$

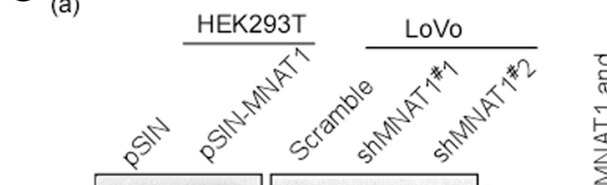

B

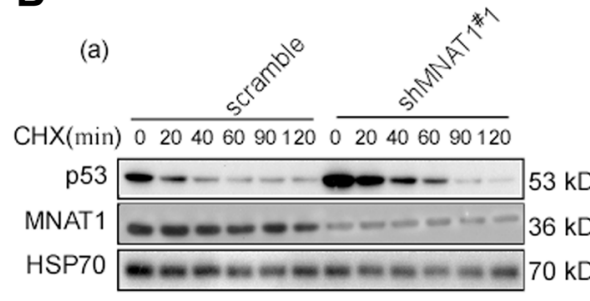

1.00 (b) $\rightarrow$ shMNAT1 ${ }^{\# 1}$

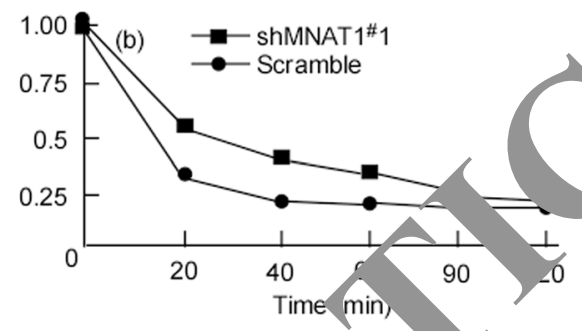

(b)

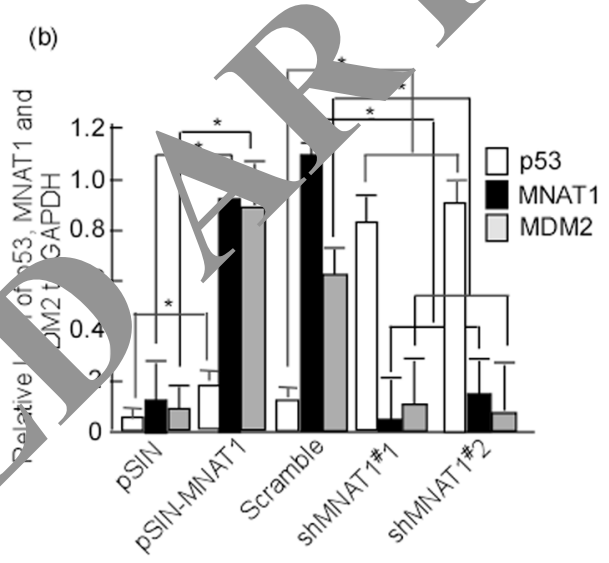

D
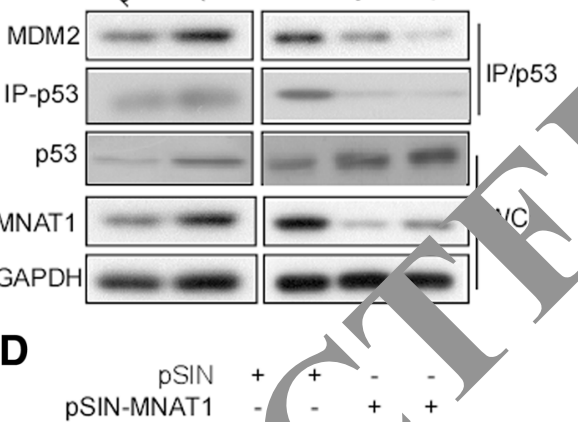
PSIN-MNAT1

ShMDM2 $2+(++)^{+}$

shcramble

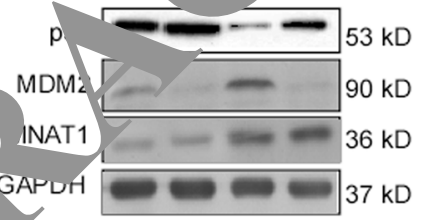

Fig. 6 MNAT1 hor half-life 1 me of p53. A, HEK293 cells were transfected with pSIN or pSIN-MNAT1, and then treated with $20 \mathrm{mg} / \mathrm{ml}$ CHX for the indicate time poli DSIN served as a control. MANT1 and p53 expressions were detected using Western-blotting (a). Quantitative analysis was cond acted on p53 le) sl in Western-blotting, the half-life time of p53 was calculated (b). B, LoVo cells were transfected with pLVX-shMNAT1 ${ }^{1} 1$, p53 and MTu ress ons in the transfected cells were detected (a). Quantitative analysis was conducted on p53 level, and the half-life time was also calculated HE 293 cells were transfected with pSIN-MNAT1, and LoVo cells were transfected with pLVX-shMNAT1" 1 or pLVX-shMNAT1" 2. p53 was munop, cipitated, and MDM2 was detected in the immunocomplexes and WCL using Western-blotting (a). Quantitative analysis was and $n$ p53 and MNAT1 expressions (b). D, MANT1-HEK293 cells were transfected with shMDM2, and p53, MDM2, MNAT1 expressions were a. ted in the transfected cells. CHX, cycloheximide; IP, immunoprecipitation; MGM2, murine double minute 2 . WCL, whole cell lysate. *, $p<0.05$

MNAT1 promotes CRC development. Determination of the underlying mechanism indicated that MNAT1 promotes CRC development through downregulating p53.

Tumor suppressor p53, encoded by TP53 gene, is a central player in cellular DNA damage responses and is mutated in 50 to $55 \%$ of human cancers, whose primary function is to promote cell-cycle arrest and induce apoptosis when necessary [47]. p53, which is known as the guardian of the genome [48], plays a critical role in inducing apoptosis and preventing oncogenesis [49]. p53 is frequently dysregulated in CRC tissues. Moreover, p53 is associated with CRC pathogenesis and advanced TNM stage, lymph nodes metastasis, and low 5-year survival 


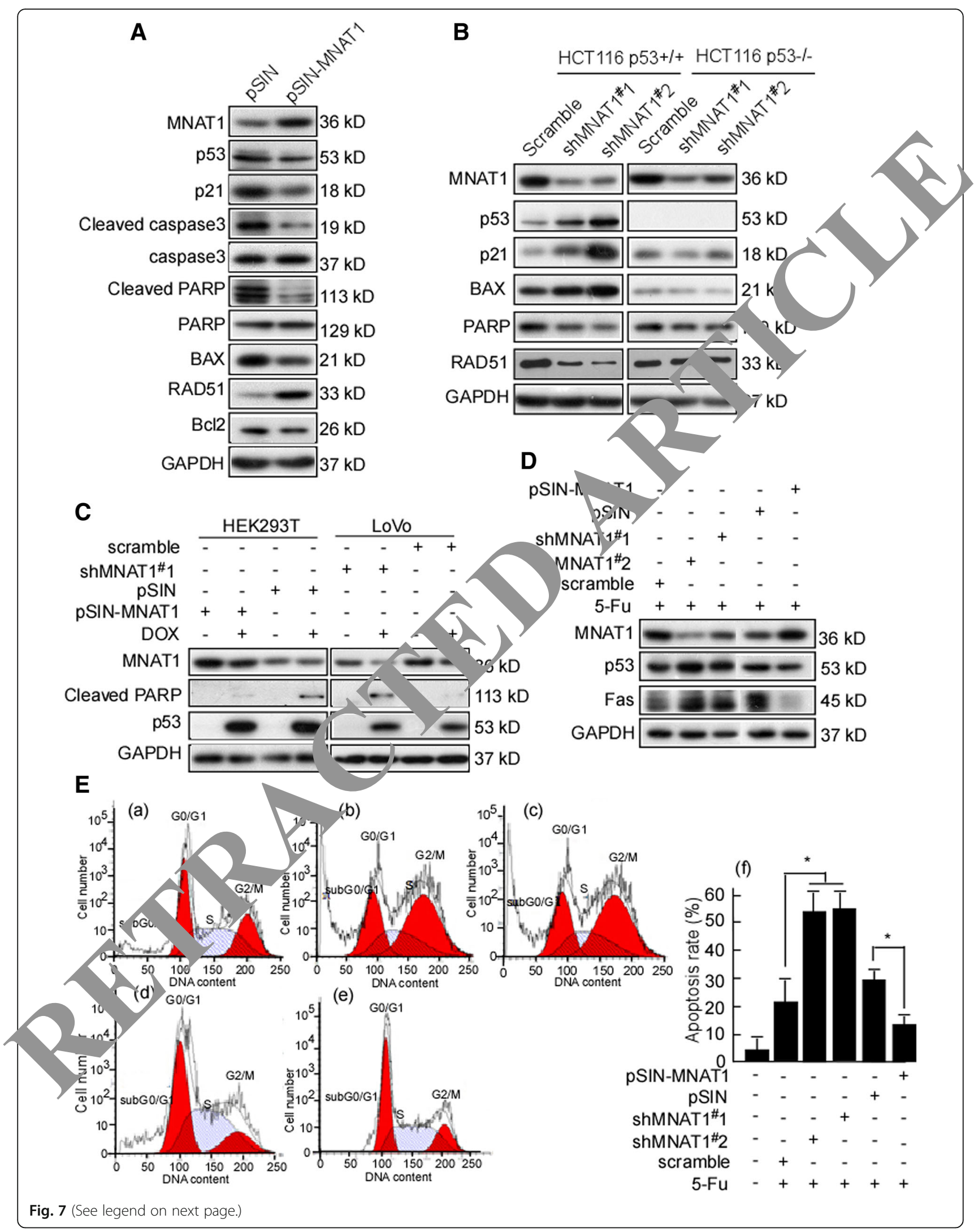


(See figure on previous page.)

Fig. 7 MNAT1 regulates p53 down-stream molecules. A, HEK293T cells were transfected with pSIN or pSIN-MANT1, and then MNAT1, p53, p21, cleaved caspase3, caspase3, cleaved PARP, PARP, BAX, RAD51, and Bcl2 were detected with Western-blotting. pSIN served as a control. B, HCT116

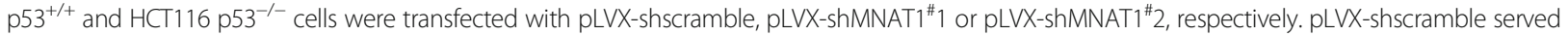

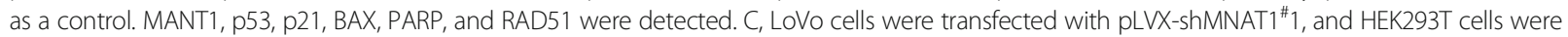
transfected with pSIN-MANT1. And then the transfected cells were treated with DOX. The treated cells were evaluated MNAT1, PARP, p53 expression. GAPDH served as a loading control. D, LoVo cells were infected with pLVX-shMNAT1 ${ }^{\# 1}$ or pLVX-shMNAT1 ${ }^{\#}$, and HEK293T cells were transfecter with pSIN-MANT1, and then treated with 5-Fu. The treated cells were evaluated MNAT1, p53, and Fas expression. E, The apoptosis of the treated "Is W ss analyzed using flow cytometry, and apoptosis rates were conducted. a, shscramble plus 5-FU; b, shMNAT1\#1 plus 5-FU; c, shMNAT1 2 plus 5-F

blank vector plus 5-FU; e, pSIN-MNAT1 plus 5-FU; f, apoptosis rates of the above treated cell. DOX, Doxorubicin; 5-Fu, 5-fluorouracil; * $p<0.05$

A

(a)

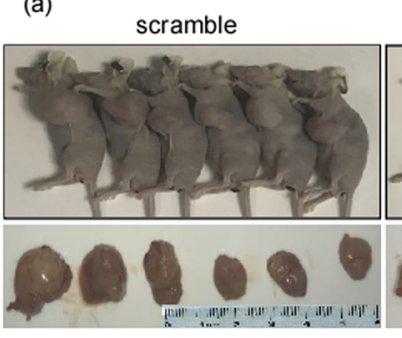

B

$(n=6)$

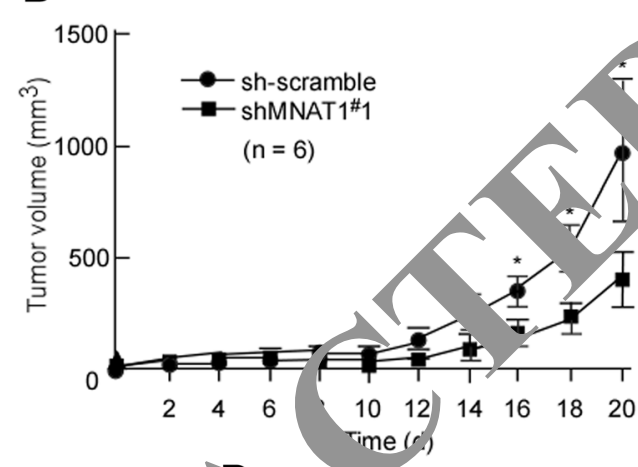

C

ShMNAT $1{ }_{1}$

(b)
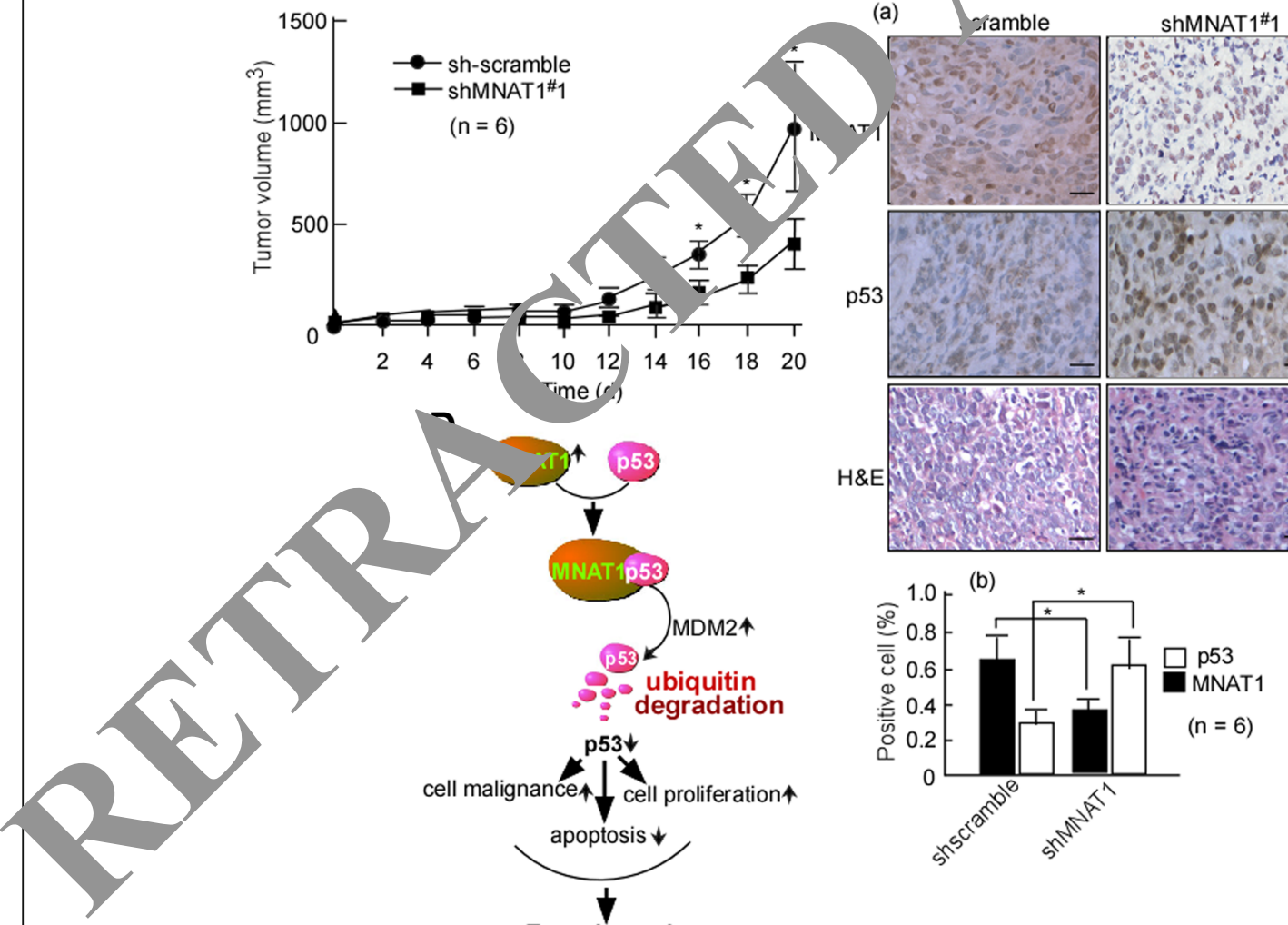

211)

(p53)
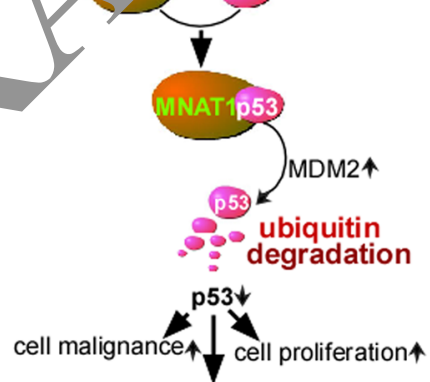

MDM2^

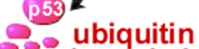

- ubiquitin

a) cramble

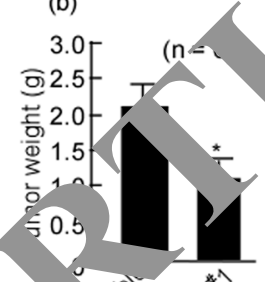

की कर
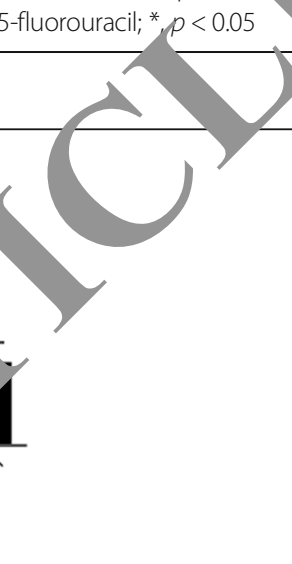
rate $[50,51]$. Of the well-known functions of $\mathrm{p} 53$, the mostly highlighted ones are the regulation of cell cycle checkpoints and inducing apoptosis under cellular stress [52]. Loss of p53 often induces oncogenesis [53-55], and promotes tumor initiation and progression [56-58]. In the present study, we found that MNAT1 shortened p53 half-lift, suggesting that MNAT1 may promote CRC carcinogenesis through decreasing p53 function. Determination of the underlying mechanism indicated that (1) MNAT1 decreases apoptosis through reducing p53 and that (2) MNAT1 regulated p53 downstream molecules, including p21, PARK, RAD51, and FAS. p21 is critical for p53-mediated G1/S boundary cell cycle arrest [59]. p53 mediates cell apoptosis by activating mitochondrial and death receptor-induced apoptotic pathways. The mitochondrial pathway is mainly regulated by binding to $\mathrm{Bcl}-2$, and releasing the cell death factors, BAX and BAK, and activate apoptosis $[60,61]$. In our study, MNAT1 not only decreased BAX, but also mediated FAS increase. FAS is a component transcriptionally regulated by p53 in the extrinsic apoptotic pathway FAS [62, 63]. MANT1-mediated apoptosis inhibition may be through the extrinsic apoptotic pathway. MNAT1-mediated p21 decrease implies that MANT1 may arrest cell cycle through p21 to participate in CRC development. These remain to be further investigated.

Interestingly, MNAT1 interacted with p53 an or moted p53 ubiquitination and degradation. MNT1 diated p53 degradation may be critica or CRy initiation and progression. p53 activity orm be ulated through ubiquitination, oxidation phosphory ation, acetylation and methylation [64-6 The key to the regulation of p53 activity is the regul $n$ of $/$ ts stability, which is mainly orchestrated $t$ ugh a network of ubiquitination reactions $[64,65]$. A s. o numerous proteins involved in p53 lation, MDM2 is the major negative regulator o 53 avel and activity $[43,67]$. MDM2 physical/sint ts with p53 and represses p53-mediated a scriptio al activation $[44,45]$ and induce p53 ubiquiti ion. The E3 ubiquitin ligase MDM2 is the most importan, regulator ubiquitin-mediated degradation f 53 (57]. MDM2 binds to p53 and ubiquitinat it pr assmal degradation [43-45]. In the present udy MNA 1 knock-in increased MDM2 interaction $w$ pos, and this interaction was decreased when $M N$ knockdown. MDM2-knockdown decreased MNAT1-reduced p53. These data suggest that MNAT1mediated p53 ubiquitin-degradation is through increasing the interaction of MDM2 with p53. MDM2 may be a critical factor in MNAT1 mediated-p53 ubiquitination.

\section{Conclusion}

MNAT1 binds to p53, promotes p53 ubiquitindegradation, and decreases its function. MNAT1- reduced p53 decreases CRC cell apoptosis and increases CRC cell growth both in vitro and in vivo, thus promoting CRC malignance (Fig. 8D). MNAT1 binding to p53 and mediating p53 ubiquitindegradation axis represents a novel molecular joint in the p53 pathway.

\section{Additional files}

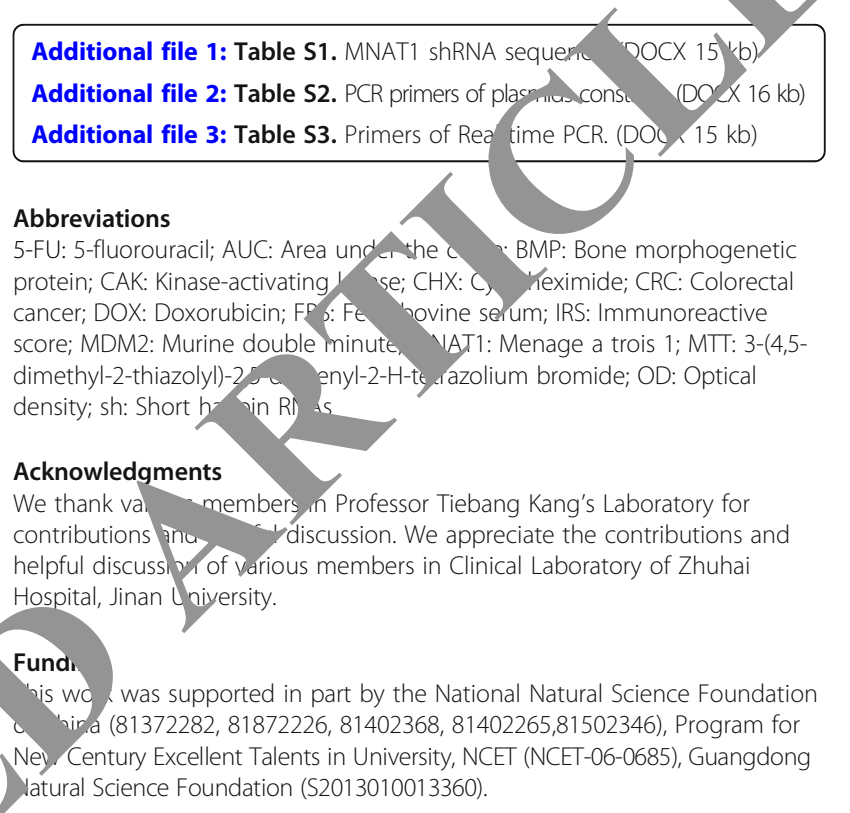

\section{Availability of data and materials}

The datasets used and/or analysed during the current study are available from the corresponding author on reasonable request.

\section{Authors' contributions}

$S Z$, JL, and $Y L$ conducted the study design. YC carried out the assays and collected the samples. SZ and JL performed the statistical analysis. ZG and KT participated the coordination of research and worked as technical consultants. SZ and YL drafted the manuscript. FT and TK revised the manuscript. All authors reviewed and approved the final manuscript.

\section{Ethics approval and consent to participate}

All procedures were consistent with the National Institutes of Health Guide and approved by institutional board with patients' written consent. This study was evaluated and approved by the Ethics Committee of the Affiliated Cancer Hospital of Xiangya Medical School, Central South University. All animal experiments were performed according to the National Institutes of Health Animal Use Guidelines on the Use of Experimental Animals.

\section{Consent for publication}

Informed consent was obtained from all individual participants included in the study.

\section{Competing interests}

The authors declare that they have no competing interests.

\section{Publisher's Note}

Springer Nature remains neutral with regard to jurisdictional claims in published maps and institutional affiliations.

\section{Author details}

'Department of Clinical Laboratory, Hunan Cancer Hospital \&The affiliated Cancer Hospital of Xiangya School of Medicine, Central South University, 
Changsha 410013, China. ${ }^{2}$ Department of Clinical Laboratory, Zhuhai Hospital, Jinan University, Zhuhai 519000, Guangdong, China. ${ }^{3}$ Hormel Institute, University of Minnesota, 801 16th Avenue NE, Austin, MN 55912, USA. ${ }^{4}$ State Key Laboratory of Oncology in South China and Department of Experimental Research, Sun Yat-sen University Cancer Center, Guangzhou 510060, Guangdong, China.

\section{Received: 16 August 2018 Accepted: 12 November 2018}

\section{Published online: 26 November 2018}

\section{References}

1. Jemal A, et al. Global cancer statistics. CA Cancer J Clin. 2011;61(2): 69-90.

2. Pancione M, Remo A, Colantuoni V. Genetic and epigenetic events generate multiple pathways in colorectal cancer progression. Patholog Res Int. 2012; 509348(10):24.

3. Ewing I, et al. The molecular genetics of colorectal cancer. Frontline Gastroenterol. 2014;5(1):26-30.

4. Vogelstein B, et al. Genetic alterations during colorectal-tumor development. N Engl J Med. 1988;319(9):525-32.

5. Medema JP, Vermeulen L. Microenvironmental regulation of stem cells in intestinal homeostasis and cancer. Nature. 2011;474(7351):318-26.

6. Markowitz SD, Bertagnolli MM. Molecular origins of cancer: molecular basis of colorectal cancer. N Engl J Med. 2009;361(25):2449-60.

7. Najdi R, Holcombe RF, Waterman ML. Wnt signaling and colon carcinogenesis: beyond APC. J Carcinog. 2011;10(5):1477-3163.

8. De Rosa M, et al. Genetics, diagnosis and management of colorectal cancer (review). Oncol Rep. 2015;34(3):1087-96.

9. Devault A, et al. MAT1 ('menage a trois') a new RING finger protein subunit stabilizing cyclin H-cdk7 complexes in starfish and Xenopus CAK. EMBO J. 1995;14(20):5027-36.

10. Shiekhattar R, et al. Cdk-activating kinase complex is a component of human transcription factor TFIIH. Nature. 1995;374(6519):283-7.

11. Tassan JP, et al. In vitro assembly of a functional human CDK7-cy complex requires MAT1, a novel $36 \mathrm{kDa}$ RING finger protein. EMBO 14(22):5608-17.

12. Yee A, et al. Molecular cloning of CDK7-associated huma a cyclindependent kinase-activating kinase (CAK) assembly facto (Cano es. 1995; 55(24):6058-62.

13. Yankulov KY, Bentley DL. Regulation of CDK7 su' strate specificity by MAT1 and TFIIH. EMBO J. 1997;16(7):1638-46.

14. Ko LJ, et al. p53 is phosphorylated by CDK7-cycl, in a p3.MMAT1dependent manner. Mol Cell Biol. 1997 $17(12) \cdot 7220$

15. Inamoto $\mathrm{S}$, et al. The cyclin-dependent tivating kinase (CAK) assembly factor, MAT1, targets and entanges $1 K$ activity on the POU domains of octamer transc factor. J Biol Chem. 1997;272(47): 29852-8.

16. Morgan DO. Principles of re Nature. 1995;374(6518):131-4.

17. Wu L, et al. RNA an isense ab. tion of MAT1 induces $G 1$ phase arrest and triggers apopto\% zortic smoo muscle cells. J Biol Chem. 1999;274(9): 5564-72.

18. Wu L, et MAT1-moa CAK activity regulates cell cycle G(1) exit. Mol Cell Bi . 2001;21(1):260-7J.

19. Zhanc to MA 1 -modulated cyclin-dependent kinase-activating kinase activity $\mathrm{a}$ regul ies neuroblastoma cell G1 arrest and neurite outgrowth. er Res. $;$;64(9):2977-83.

BU $D$ et at. Distinct regions of MAT1 regulate cdk7 kinase and TFIIH on activities. J Biol Chem. 2000;275(30):22815-23.

21. $a$, et al. Retinoid-induced G1 arrest and differentiation activation are as, jociated with a switch to cyclin-dependent kinase-activating kinase hypophosphorylation of retinoic acid receptor alpha. J Biol Chem. 2002; 277(45):43369-76.

22. Wang JG, et al. Retinoic acid induces leukemia cell G1 arrest and transition into differentiation by inhibiting cyclin-dependent kinase-activating kinase binding and phosphorylation of PML/RARalpha. FASEB J. 2006; 20(12):2142-4.

23. Luo $\mathrm{P}$, et al. Intrinsic retinoic acid receptor alpha-cyclin-dependent kinase-activating kinase signaling involves coordination of the restricted proliferation and granulocytic differentiation of human hematopoietic stem cells. Stem Cells. 2007;25(10):2628-37.
24. Lou S, et al. The lost intrinsic fragmentation of MAT1 protein during granulopoiesis promotes the growth and metastasis of leukemic myeloblasts. Stem Cells. 2013;31(9):1942-53.

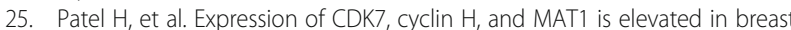
Cancer and is prognostic in estrogen receptor-positive breast Cancer. Clin Cancer Res. 2016;22(23):5929-38.

26. Hong J, et al. CHK1 targets spleen tyrosine kinase (L) for proteolysis in hepatocellular carcinoma. J Clin Invest. 2012;122(6):2165-75.

27. Zhao SH, et al. Basigin-2 is the predominant basigin isoform th promo tumor cell migration and invasion and correlates with poor for epithelial ovarian cancer. J Transl Med. 2013;11:92.

28. Klopfleisch R. Multiparametric and semiquantitative so fring systems to ne evaluation of mouse model histopathology--a syster. review. B MC Vet Res. 2013;9:123.

29. Fu D, et al. Mdm2 promotes myogenesis th ough the ubiqu ation and degradation of CCAAT/enhancer-binding $\mathrm{p}$ tein beta. JBiol Chem. 2015; 290(16):10200-7.

30. Xu S, et al. hSSB1 regulates both the bility uranscriptional activity of p53. Cell Res. 2013.23(3):423.

31. Kang T, et al. GSK-3 beta tar $\subseteq$ Cdc25A to rquitin-mediated proteolysis, and GSK-3 beta inactivat in a vas with 2 dc25A overproduction in human cancers. Cancer Cell. 200a (1):36-47.

32. Xu M, et al. Revers t of adeno, "us-mediated human interleukin 24 transfection on cisp tin resistance of A549/DDP lung cancer cells. Oncol Rep. 2017

33. Tang J, et al. Parado, role of CBX8 in proliferation and metastasis of colored ancer. Onco arget. 2014;5(21):10778-90.

34. He Z, et $(\cdot)$, nvel target of (-)-epigallocatechin gallate in the inhibition Jf B6 9.41 cell transformation. Mol Carcinog. 2008;47(3):172-83.

35. Tang FQ, et al, HSP70 and mucin 5B: novel protein targets of N,N'nitrosopiperazine-induced nasopharyngeal tumorigenesis. Cancer Sci. ; 100(2):216-24

Ta $\mathrm{F}$, et al. $\mathrm{N}, \mathrm{N}^{\prime}$-dinitrosopiperazine-mediated ezrin protein osphorylation via activation of rho kinase and protein kinase $\mathrm{C}$ is nvolved in metastasis of nasopharyngeal carcinoma 6-10B cells. J Biol Chem. 2011;286(42):36956-67.

37. Xu S, et al. hSSB1 binds and protects p21 from ubiquitin-mediated degradation and positively correlates with p21 in human hepatocellular carcinomas. Oncogene. 2011;30(19):2219-29.

38. Johmura Y, et al. SCF(Fbxo22)-KDM4A targets methylated p53 for degradation and regulates senescence. Nat Commun. 2016;7:10574

39. Shamseddine AA, et al. P53-dependent upregulation of neutral sphingomyelinase-2: role in doxorubicin-induced growth arrest. Cell Death Dis. 2015;6:e1947.

40. Hochstrasser M. Ubiquitin, proteasomes, and the regulation of intracellular protein degradation. Curr Opin Cell Biol. 1995;7(2):215-23.

41. Ciechanover A. The ubiquitin-proteasome proteolytic pathway. Cell. 1994; 79(1):13-21.

42. Orlowski RZ, Dees EC. The role of the ubiquitination-proteasome pathway in breast cancer: applying drugs that affect the ubiquitin-proteasome pathway to the therapy of breast cancer. Breast Cancer Res. 2003;5(1):1-7.

43. Wade M, Li YC, Wahl GM. MDM2, MDMX and p53 in oncogenesis and cancer therapy. Nat Rev Cancer. 2013;13(2):83-96.

44. Momand J, et al. The mdm-2 oncogene product forms a complex with the p53 protein and inhibits p53-mediated transactivation. Cell. 1992;69(7): $1237-45$.

45. Oliner JD, et al. Oncoprotein MDM2 conceals the activation domain of tumour suppressor p53. Nature. 1993;362(6423):857-60.

46. Tacar O, Sriamornsak P, Dass CR. Doxorubicin: an update on anticancer molecular action, toxicity and novel drug delivery systems. J Pharm Pharmacol. 2013;65(2):157-70.

47. Wang X, Simpson ER, Brown KA. p53: protection against tumor growth beyond effects on cell cycle and apoptosis. Cancer Res. 2015; 75(23):5001-7.

48. Efeyan A, Serrano M. p53: guardian of the genome and policeman of the oncogenes. Cell Cycle. 2007;6(9):1006-10.

49. Meulmeester E, Jochemsen AG. p53: a guide to apoptosis. Curr Cancer Drug Targets. 2008:8(2):87-97.

50. Bartek J, et al. Aberrant expression of the p53 oncoprotein is a common feature of a wide spectrum of human malignancies. Oncogene. 1991;6(9): 1699-703. 
51. Wen S, et al. p53 increase mitochondrial copy number via up-regulation of mitochondrial transcription factor A in colorectal cancer. Oncotarget. 2016; 7(10):12514.

52. Levine AJ. p53, the cellular gatekeeper for growth and division. Cell. 1997; 88(3):323-31.

53. Sarasqueta AF, et al. Integral analysis of p53 and its value as prognostic factor in sporadic colon cancer. BMC Cancer. 2013;13(277):1471-2407.

54. Liu BW, et al. Prognostic effect of p53 expression in patients with completely resected colorectal cancer. Tumour Biol. 2014;35(10):9893-6.

55. Stefancikova $L$, et al. Prognostic impact of p53 aberrations for R-CHOPtreated patients with diffuse large B-cell lymphoma. Int J Oncol. 2011; 39(6):1413-20

56. Harvey $\mathrm{M}$, et al. Genetic background alters the spectrum of tumors that develop in p53-deficient mice. FASEB J. 1993;7(10):938-43.

57. Jacks T, et al. Tumor spectrum analysis in p53-mutant mice. Curr Biol. 1994; $4(1): 1-7$

58. Strong LC. General keynote: hereditary cancer: lessons from li-Fraumeni syndrome. Gynecol Oncol. 2003;88(1 Pt 2):S11-3.

59. Abbas T, Dutta A. p21 in cancer: intricate networks and multiple activities. Nat Rev Cancer. 2009;9(6):400-14.

60. Nakano K, Vousden KH. PUMA, a novel proapoptotic gene, is induced by p53. Mol Cell. 2001;7(3):683-94.

61. Bouvard V, et al. Tissue and cell-specific expression of the p53-target genes: bax, fas, mdm2 and waf1/p21, before and following ionising irradiation in mice. Oncogene. 2000;19(5):649-60.

62. Muller $\mathrm{M}$, et al. p53 activates the CD95 (APO-1/Fas) gene in response to DNA damage by anticancer drugs. J Exp Med. 1998;188(11):2033-45.

63. Aubrey BJ, et al. How does p53 induce apoptosis and how does this relate to p53-mediated tumour suppression? Cell Death Differ. 2018;25(1):104-13.

64. Hock AK, Vousden $\mathrm{KH}$. The role of ubiquitin modification in the regulation of p53. Biochim Biophys Acta. 2014;1:137-49.

65. Pant V, Lozano G. Limiting the power of p53 through the ubiquitin proteasome pathway. Genes Dev. 2014;28(16):1739-51.

66. Tang Y, et al. Acetylation is indispensable for p53 activation. Cell. 2008. 133(4):612-26

67. Kruse JP, Gu W. Modes of p53 regulation. Cell. 2009;137(4):609-22.

Ready to submit your research? Choose BMC and benefit from:

- fast, convenient online submission

- thorough peer review by experienced researchers in your field

- rapid publication on acceptance

- support for research data, including large and complex data types

- gold Open Access which fosters wider collaboration and increased citations

- maximum visibility for your research: over $100 \mathrm{M}$ website views per year

At $\mathrm{BMC}$, research is always in progress.

Learn more biomedcentral.com/submissions 